\section{Pembuatan Termokopel \\ Berbahan Nikel (Ni) dan Tembaga (Cu) Sebagai Sensor Temperatur}

\author{
Hadi Santoso ${ }^{1}$ dan Ruslim² \\ Fakultas Teknik, Universitas Borneo Tarakan ${ }^{1,2}$ \\ Email: hadisantoso@borneo.ac.id
}

\begin{abstract}
Abstrak. Telah dilakukan perancangan sebuah termokopel berbahan Nikel (Ni) -Tembaga (Cu) dan dilakukan analisa pengukuran temperatur dalam mempelajari konsep Termokopel. Termokopel kawat nikel dan tembaga dapat bekerja sesuai prinsip dasar termokopel yakni menghasilkan arus listrik dari perbedaan temperature diantara dua kaki kawat logam yang berbeda. Termokopel ini dapat teruji dalam mengukur temperatur hingga $225^{\circ} \mathrm{C}$ dengan baik. Penggunaan termokopel untuk mendeteksi kenaikan dan penurunan temperatur dengan nilai regresi hampir mendekati 1 dimana tegangan kenaikan dan penurunan suhu berkisar 65 hingga $513 \mu$ Volt.
\end{abstract}

Kata Kunci: Termokopel, Temperatur, Tegangan, Nikel, Tembaga

\section{INDONESIAN JOURNAL OF FUNDAMENTAL SCIENCES (IJFS)}

\section{E-ISSN: 2621-6728 \\ P-ISSN: 2621-671X}

Submitted: February, $15^{\text {th }}, 2019$

Accepted : March, 23 ${ }^{\text {th }}, 2019$

Abstract. The design of a Nickel (Ni) Copper (Cu) thermocouples has been carried out for temperature sensors is carried out in studying the concept of Thermocouples.. The sensor will be made of two different types of materials namely nickel and copper. Nickel and copper wire thermocouples can work in accordance with the basic principle of the thermocouple, which produces electric current from a difference in temperature between two different metal wire legs. Thermocouples can measure at temperature of $35^{\circ} \mathrm{C}$ to $2 \mathbf{2 5}^{\circ} \mathrm{C}$. The use of thermocouples to detect increases and decreases in temperature with regression values almost close to 1 where voltage increases and decreases in temperature range from 65 to 513 $\mu$ Volt. 


\section{PENDAHULUAN}

Termokopel merupakan sebuah alat yang digunakan untuk mengukur temperatur/suhu. Termokopel memiliki output berupa arus listrik sehingga pengkonversiannya dapat secara digital. Konsep kerja dasar termokopel pertama kali ditemukan oleh Seebeck (1821) yang menemukan bahwa sebuah konduktor yang diberi perbedaan panas secara gradien akan menghasilkan tegangan listrik. Hal ini disebut sebagai efek termoelektrik. Konduktor tambahan ini kemudian akan mengalami gradiasi suhu, dan mengalami perubahan tegangan secara berkebalikan dengan perbedaan temperatur benda. Bila suatu rangkaian yang terdiri dari dua buah logam yang tidak sejenis dan bila temperatur pada sambungan-sambungan dari kedua kawat tersebut tidak sama, maka akan ada gaya listrik.

Menurut Rosman (2018), termokopel bekerja berdasarkan pembangkitan tenaga listrik pada titik sambung dua buah logam yang tidak sama (titik panas/titk ukur). Ujung lain dari logam tersebut sering disebut titik referensi (titik dingin) dimana temperaturnya konstan. Umumnya termokopel digunakan untuk mengukur temperatur berdasarkan perubahan temperatur menjadi sinyal listrik. Bila antara titik referensi dan titik ukur terdapat perbedaan temperatur, maka akan timbul GGL yang menyebabkan adanya arus pada rangkaian. Bila titik referensi ditutup dengan cara menghubungkannya dengan sebuah alat pencatat maka penunjukan alat ukur akan sebanding dengan selisih temperatur antara ujung panas (titik ukur) dan ujung dingin (titik referensi).

Terdapat beberapa jenis termokopel diantaranya sebagai berikut; (1) Tipe K [Chromel ( $\mathrm{Ni}-\mathrm{Cr}$ alloy) - Alumel (Ni-Al alloy)] mengukur suhu (-200) sampai $1.200^{\circ} \mathrm{C}$. (2)Tipe $\mathrm{E}$ [Chromel - Constantan (Cu-Ni alloy)] digunakan pada temperatur rendah. (3) Tipe J [Iron - Constantan] mengukur temperatur (-40) sampai $750^{\circ} \mathrm{C}$. (4) Tipe $\mathrm{N}$ [Nicrosil (Ni-Cr-Si alloy) - Nisil (Ni-Si-alloy)] mengukur suhu di atas $1200^{\circ} \mathrm{C}$. (5). Type $\mathrm{B}$ [Platinum-Rhodium(Pt-Rh)] mengukur hingga $1800^{\circ} \mathrm{C}$ namun tidak dapat mengukur dibawah $50^{\circ} \mathrm{C}$. (6). Type R [Platinum-(Platinum-7\% Rhodium)] mengukur suhu di atas $1600^{\circ} \mathrm{C}$. (7) Type S [Platinum-(Platinum-10\% Rhodium)] mengukur suhu di atas $1600^{\circ} \mathrm{C}$. (8) Type $\mathrm{T}$ [Copper-Constantan] mengukur antara (-200) hingga $350^{\circ} \mathrm{C}$.

Termokopel yang akan berbahan Kawat Nikel dan Kawat Tembaga, tidak termasuk dalam tipe-tipe termokopel yang ada diatas. Namun termokopel yang akan dibangun memiliki prinsip kerja yang sama dalam menghasilkan listrik. Tujuan dari penelitian ini adalah melihat sejauh mana suhu yang dapat dikuru dan menganalisa kemampuannya dalam mengukur kenaikan maupun penurunan suatu temperatur.

\section{METODE PENELITIAN}

Kawat tembaga dan nikel dibuat sedemikian rupa seperti pada gambar 1, dimana spesifikasi dari termokopel yang digunakan dalam penelitian ini adalah dua buah kawat tembaga dan besi dengan panjang $75 \mathrm{~cm}$, dan seutas kawat nikel dengan panjang $30 \mathrm{~cm}$. Bahan lainnya yang digunakan adalah port yang nanti akan disambungkan dengan multimeter, pelindung kawat, serta head sensor. 


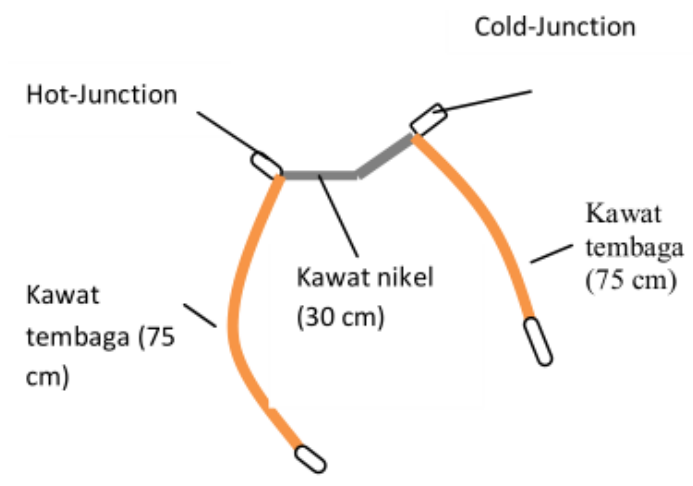

Gambar 1. Perancangan Termokopel

Pembuatan sensor dimulai dengan menyambungkan kawat tembaga dengan nikel susuai gambar 1. Kemudian memberikan pengaman kawat, menyambungkan dengan port dan head sensor. Proses penggunaan dan pengabilan data termokopel ini diawali dengan memasukan salah satu sambungan tembaga kedalam es sebagai cold-junction dengan tujuan untuk menjaga tetap konstan sehingga akan menjadi temperatur referensi. Dalam penelitian ini, temperatur referensi adalah $25^{\circ} \mathrm{C}$. Bagian lainnya (hot-junction) digunakan sebagai sensor utama pendeteksi perubahan temperatur yang ingin diukur. Dapat digunakan dengan memberi kalor dari panas api korek. Bagian ujung tembaga lainnya dari termokopel selanjutnya dihubungkan dengan multimeter dengan mode inputan temperatur. Semua proses sesuai gambar 2.

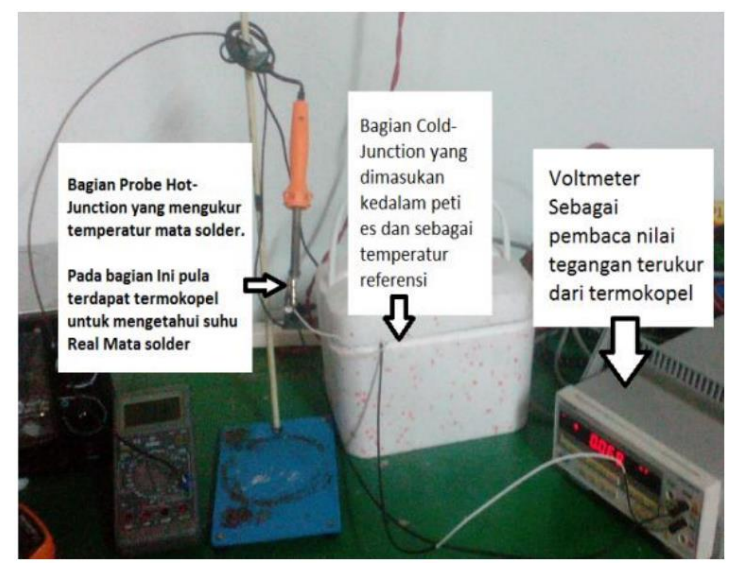

Gambar 2.

Perangkat Pengukuran Temperatur dengan Termokopel

Prinsip pengambilan data yakni mencatat data tegangan keluaran tiap kenaikan temperatur dengan kelipatan $5^{\circ} C$, dari temperatur ruangan hingga batas kemampuan ukur termokopel. Diukur pula data tegangan keluaran saat suhu mengalami penurunan (tiap kelipatan $5^{\circ} \mathrm{C}$ hingga mencapai temperatur ruangan, yakni $35^{\circ} \mathrm{C}$. Untuk logam yang biasa digunakan dalam termokopel, tegangan output meningkat hampir linear dengan perbedaan suhu $(\Delta T)$ dalam rentang suhu yang terbatas yang dipengaruhu oleh koefisien a. Hubungannya antara $V$, a dan $T$ berdasarkan persamaan berikut; 


$$
V_{\text {terukur }}=\alpha \cdot\left(T_{\text {terukur }}-T_{\text {referensi }}\right)
$$

Dimana $\mathrm{T}$ referensi adalah $\mathrm{T}$ Reference junction (cold junction), merupakan sambungan acuan yang temperaturnya dijaga konstan dan biasanya diberi temperatur yang dingin.

\section{HASIL DAN PEMBAHASAN}

Data yang diperoleh berdasarkan kenaikan dan penurunan suhu adalah sebagai berikut;

Tabel 1. Kenaikan Temperatur

\begin{tabular}{|c|c|c|}
\hline $\begin{array}{c}\text { Kenaikan } \\
\text { Temperatur } \\
\left({ }^{o} C\right)\end{array}$ & $\begin{array}{c}\text { Tegangan } \\
(\mu \mathrm{V})\end{array}$ & a.V \\
\hline 35 & 65 & 128,030 \\
\hline 40 & 83 & 181,289 \\
\hline 45 & 98 & 223,349 \\
\hline 50 & 115 & 275,521 \\
\hline 55 & 129 & 313,981 \\
\hline 60 & 132 & 300,414 \\
\hline 65 & 146 & 338,349 \\
\hline 70 & 160 & 376,471 \\
\hline 75 & 172 & 405,260 \\
\hline 80 & 201 & 517,962 \\
\hline 85 & 213 & 546,614 \\
\hline 90 & 224 & 570,182 \\
\hline 95 & 234 & 588,774 \\
\hline 100 & 246 & 617,510 \\
\hline 105 & 258 & 646,252 \\
\hline 110 & 268 & 665,037 \\
\hline 115 & 278 & 683,929 \\
\hline 120 & 298 & 752,576 \\
\hline 125 & 300 & 731,707 \\
\hline 130 & 312 & 760,500 \\
\hline 135 & 322 & 779,579 \\
\hline 140 & 334 & 808,377 \\
\hline 145 & 346 & 837,175 \\
\hline 150 & 355 & 851,520 \\
\hline 155 & 364 & 865,987 \\
\hline 160 & 376 & 894,785 \\
\hline 165 & 385 & 909,356 \\
\hline 170 & 394 & 924,024 \\
\hline
\end{tabular}


63 Indonesian Journal of Fundamental Sciences Vol.5, No.1, April 2019

\begin{tabular}{ccc}
\hline 175 & 406 & 952,809 \\
\hline 180 & 415 & 967,556 \\
\hline 185 & 426 & 991,672 \\
\hline 190 & 437 & 1015,793 \\
\hline 195 & 448 & 1039,917 \\
\hline 200 & 460 & 1068,687 \\
\hline 205 & 472 & 1097,458 \\
\hline 210 & 481 & 1112,313 \\
\hline 215 & 492 & 1136,451 \\
\hline 220 & 502 & 1155,982 \\
\hline
\end{tabular}

Berdasarkan pada tabel diatas diperoleh rerata temperatur untuk kenaikan dibuat grafik hubungan antara perubahan tegangan akibat perubahan termperatur saat naik yang terlihat pada gambar 3 .

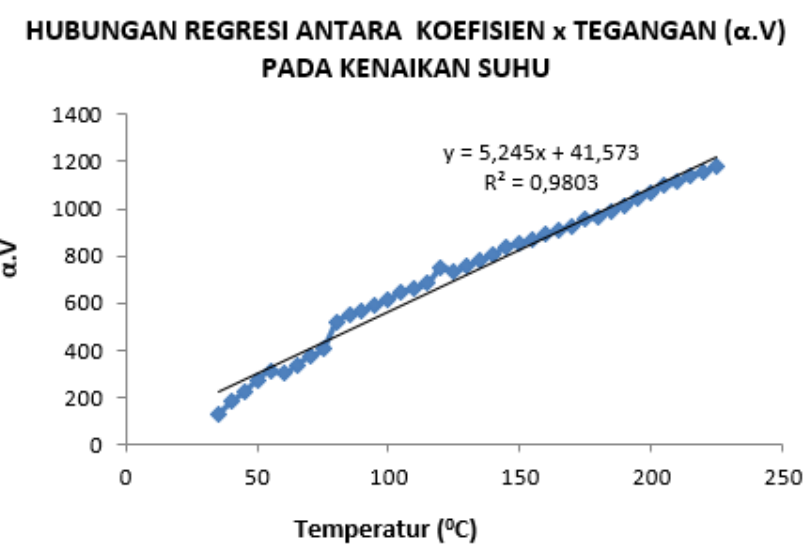

Gambar 3.

Grafik hubungan kenaikan temperature antara koefisien dan tegangan

Selanjutnya untuk data saat temperatur turun dapat dilihat pada tabel 2 berikut:

Tabel 2. Penurunan Temperatur

\begin{tabular}{ccr}
\hline $\begin{array}{c}\text { Penurunan } \\
\text { Temperatur }\left({ }^{\circ} C\right)\end{array}$ & $\begin{array}{c}\text { Tegangan } \\
(\mu \mathrm{V})\end{array}$ & \multicolumn{1}{c}{ a.V } \\
\hline 225 & 513 & 1180,130 \\
\hline 220 & 488 & 1092,404 \\
\hline 215 & 472 & 1045,934 \\
\hline 210 & 458 & 1008,481 \\
\hline 205 & 445 & 975,493 \\
\hline 200 & 430 & 933,838 \\
\hline 195 & 415 & 892,358 \\
\hline
\end{tabular}




\begin{tabular}{|c|c|c|}
\hline 190 & 398 & 842,574 \\
\hline 185 & 389 & 826,891 \\
\hline 180 & 373 & 781,624 \\
\hline 175 & 359 & 744,977 \\
\hline 170 & 344 & 704,381 \\
\hline 165 & 331 & 672,153 \\
\hline 160 & 320 & 648,101 \\
\hline 155 & 308 & 620,026 \\
\hline 150 & 290 & 568,243 \\
\hline 145 & 281 & 552,175 \\
\hline 140 & 271 & 532,181 \\
\hline 135 & 261 & 512,188 \\
\hline 130 & 250 & 488,281 \\
\hline 125 & 239 & 464,398 \\
\hline 120 & 225 & 429,025 \\
\hline 115 & 217 & 416,717 \\
\hline 110 & 207 & 396,750 \\
\hline 105 & 196 & 372,971 \\
\hline 100 & 187 & 356,827 \\
\hline 95 & 178 & 340,688 \\
\hline 90 & 168 & 320,727 \\
\hline 85 & 159 & 304,590 \\
\hline 80 & 150 & 288,462 \\
\hline 75 & 139 & 264,671 \\
\hline 70 & 128 & 240,941 \\
\hline 65 & 120 & 228,571 \\
\hline 60 & 110 & 208,621 \\
\hline 55 & 102 & 196,302 \\
\hline 50 & 93 & 180,188 \\
\hline 45 & 84 & 164,093 \\
\hline 40 & 74 & 144,105 \\
\hline 35 & 66 & 132,000 \\
\hline
\end{tabular}

Berdasarkan pada tabel diatas diperoleh rerata temperatur untuk kenaikan dibuat grafik hubungan antara perubahan tegangan akibat perubahan termperatur saat naik yang terlihat pada gambar 4 . 


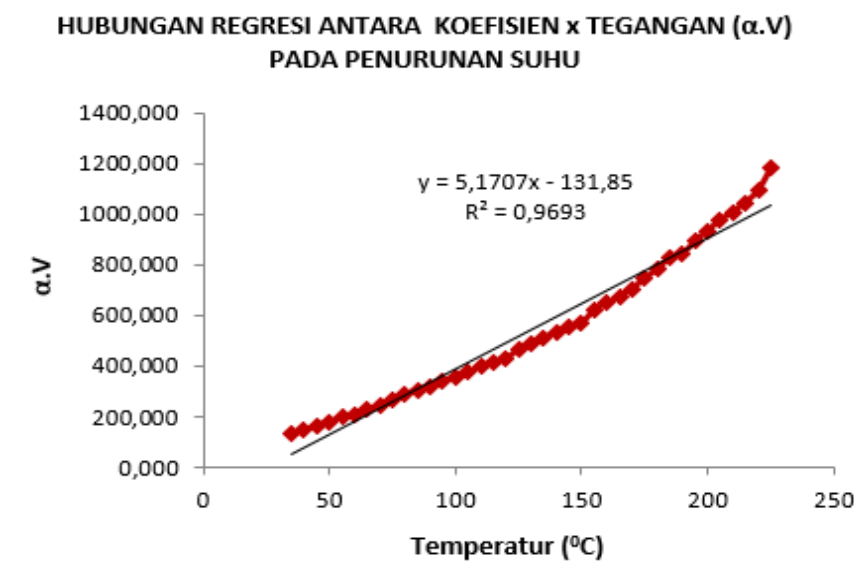

Gambar 4.

Grafik hubungan penurunan suhu antara koefisien dan tegangan

Perbedaaan suhu akan menyebabkan timbulnya tegangan pada probe ujung termokopel yang dihubungkan ke voltmeter digital yang memiliki kemampuan pembacaan tegangan yang cukup kecil. Dibutuhkan voltmeter yang dapat membaca tegangan relatif kecil, karena tegangan yang dihasilkan termokopel ini yakni terendah adalah $65 \mu$ Volt pada temperatur kamar $35^{\circ} \mathrm{C}$ dan tegangan terukur tertinggi berkisar $225^{\circ} \mathrm{C}$ adalah $250 \mu$ Volt. Berdasarkan pengamatan, temperatur $225^{\circ} \mathrm{C}$ bukan merupakan suhu maksimum yang dapat diukur oleh termokopel ini. Penulis berasumsi bahwa suhu $225^{\circ} \mathrm{C}$ ini merupakan kemampuan alat pemanas sebagai sumber energi panas yang diukur hanya memiliki batas maksimum mencapai suhu $225^{\circ} \mathrm{C}$. Jadi termokopel yang dibuat belum diperoleh informasi batas suhu maksimumnya. Begitu pula temperatur terendah. Termokopel yang dicoba hanya sampai batas temperatur ruangan saja yakni $35^{\circ} \mathrm{C}$, termokopel ini belum dicoba dalam mengukur temperatur yang lebih rendah lagi bahkan hingga mendekati temperatur minus. temperatur yang dicapai sekitar $225^{\circ} \mathrm{C}$ mendekati nilai temperatur yang dapat diukur oleh termokopel berbahan besi (Fe) dan tembaga (Cu) dengan temperatur naik yang mencapai $231^{\circ} \mathrm{C}$ (Rosman, 2018).

Melalui data temperatur referensi terukur dari probecold-junction yang dicelupkan dalam es yakni $25^{\circ} \mathrm{C}$ dan dari data tabel 1 dan 2 maka akan dapat kita masukan ke dalam persamaan diatas dalam memperoleh koefisien $\alpha$. Berdasarkan hasil perhitungan rata-rata nilai $\alpha$ menunjukan bahwa termokopel ini memiliki nilai keofisien $a$ untuk kenaikan temperatur adalah 1.97 dan penurunan suhunya adalah 2. Hubungan regresi untuk kedua persamaan dalam grafik kenaikan dan penurunan temperatur keduanya memiliki nilai $\mathrm{R}^{2}$ yang mendekati 1 yang menunjukan bahwa hubungan linier sangat baik. 


\section{KESIMPULAN}

1. Termokopel kawat nikel dan tembaga dapat bekerja sesuai prinsip dasar termokopel yakni menghasilkan arus listrik dari perbedaan temperature diantara dua kaki kawat logam yang berbeda.

2. Termokopel ini dapat teruji dalam mengukur temperatur $35^{\circ} \mathrm{C}$ hingga $225^{\circ} \mathrm{C}$ dengan baik.

3. Penggunaan termokopel untuk mendeteksi kenaikan dan penurunan temperatur dengan nilai regresi hampir mendekati 1 dimana tegangan kenaikan dan penurunan suhu berkisar 65 hingga $513 \mu$ Volt.

\section{DAFTAR PUSTAKA}

Benedict, R. P. (1984). Fundamentals of Temperature, Pressure, and Flow Measurements, 3 rd ed. JohnWiley \& Sons, New York.

Fraden, Jacob. (2003). Handbook Of Modern Sensors (Physics, Designs, and Application), Springer-Verlag New York, Inc.

Kariem, Saeful dan Sunardi. (2003). Penentuan Elektromotansi Thermal Beberapa Jenis Termokopel Dengan Pasangan Logam Yang Bervariasi. UPI. Bandung.

Rosman, A. (2018). Perancangan Termokopel Berbahan Besi (Fe) dan Tembaga (Cu) Untuk Sensor Temperatur. Indonesian Journal of Fundamental Sciences, 4(2), 120127. 